\title{
A VOZ DE NORA BARNACLE
}

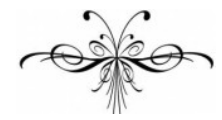 \\ DirCe Waltrick Do AMARANTE
}

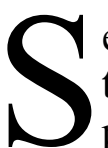
egundo Brenda Maddox, biógrafa de Nora Barnacle, "Nora não tinha diário. $\mathrm{O}$ que poderia reconstruir sua personalidade pertencia em grande parte a seu cunhado Stanislaus Joyce. Foi ele quem salvou, e sua viúva depois vendeu para Cornell, a ampla coleção de cartas privadas que revela quase tudo que se sabe sobre fatos da família de Nora, seu namoro e seu relacionamento com James Joyce". ${ }^{1}$

Grande parte da correspondência entre o casal foi escrita apenas por Joyce, já que Nora não gostava de redigir cartas e só o fazia por necessidade. Não são raras as vezes em que Joyce, nas cartas à companheira, a chama de "caladinha", "silenciosa" e implora que ela the escreva.

As cartas de Joyce a Nora, reunidas neste volume, teriam, como todas as correspondências amorosas, de acordo com a tese de Roland Barthes, a seguinte característica: "eu falo e você me escuta, logo nós somos", ${ }^{2}$ numa frase de Ponge, retomada pelo crítico francês. Portanto, prossegue Barthes,"o discurso amoroso sufoca o outro, que não encontra nenhum espaço para a sua própria palavra sob esse dizer maciço". ${ }^{3}$ Ou seja, "o outro é desfigurado por seu mutismo, como naqueles sonhos pavorosos nos quais tal pessoa amada aparece com a parte inferior do rosto apagada, privada de boca; e eu que falo, sou também desfigurado: o solilóquio faz de mim um monstro, uma enorme língua."

Ao mesmo tempo, entretanto, como afirma o pensador italiano Giorgio Agamben, "só as palavras nos põem em contato com as coisas mudas". Nesse aspecto, as cartas de Joyce dão visibilidade a Nora Barnacle, sua companheira de vida, nascida em Galway em 21 ou 22 (igreja e estado não estão de acordo

\footnotetext{
${ }^{1}$ Maddox, Brenda. Nora: the real life of Molly Bloom. Nova York: A Mariner Book, 1988, p. 385.

${ }^{2}$ Barthes, Roland. Fragmentos de um discurso amoroso. São Paulo: Martins Fontes, 2003, p. 252.

${ }^{3}$ Idem, ibidem.

${ }^{4}$ Barthes, Roland, op. cit., p. 253.

${ }^{5}$ Agamben, Giorgio. Ideia da prosa. Lisboa: Cotovia, 1999, p. 112.
} 


\section{DiRCE WALTRICK DO AMARANTE}

quanto ao dia) de março de 1884 , filha de um padeiro analfabeto, ${ }^{6}$ Thomas Barnacle, e de uma costureira, Annie (abreviatura de Honoraria) Barnacle, nascida Healy.

Quando Nora tinha dois anos, foi morar com a avó materna, Catherine Mortimer Healy, pois sua mãe precisava cuidar dos outros filhos menores do casal. A mudança para a casa da avó teria sido o primeiro exílio de Nora, o qual moldou substancialmente sua personalidade.

Numa carta de 3 de dezembro de 1904, enviada de Pola para seu irmão Stanislaus Joyce, o escritor relata alguns detalhes sobre a família de Nora:

O pai de Nora é um padeiro. Eles são uma família de sete. Papai tinha uma loja, mas bebia a valer todas as tortas e pães. A família da mãe é "distinta" e [...] interveio. Arresto do papai. Tio Michael $^{7}$ ajudou a sra. e as crianças, enquanto papai assava e bebia num lugar distante de Connacht. Tio M. é rico. Papai é tratado muito desdenhosamente pela família. Nora diz que sua mãe não queria mais ficar com ele. Nora não vivia na casa mas com sua avó que lhe deixou algum dinheiro. ${ }^{8}$

Embora na casa da avó Nora vivesse com bastante conforto, o que a casa materna dificilmente lhe ofereceria, ela nunca perdoou a mãe por tê-la "mandando embora" de casa. Por isso não se despediu dela quando deixou Galway. ${ }^{9}$

Nora só se reconciliaria com a mãe anos mais tarde, quando já vivia com James Joyce na Itália. Numa das viagens de Joyce à Irlanda, ela pediu que ele visitasse sua família e apresentasse Giorgio, o filho de ambos, a seus parentes. Joyce conta numa carta sua impressão da sogra, muito favorável, aliás:

Uma hora atrás eu estava cantando a tua canção The Lass of Aughrim ("A moça de Aughrim"). Meus olhos se enchem de lágrimas e minha voz treme de emoção quando canto essa ária encantadora. Valeu a pena ter vindo à Irlanda para aprendê-la com a tua pobre e amável mãe - de quem gosto muito, Nora querida.

Ao contrário do que se pensa sobre Nora "É parte do mito da camareira que fugiu com o artista dizer que Nora era ignorante e inculta." ${ }^{\prime 0}$-, ela não era muito diferente das moças da sua época e frequentou a escola até os doze anos, ou seja, como lembra Maddox, "teve o máximo de educação escolar que era acessível sem remuneração às garotas daqueles dias". ${ }^{11}$ Moças da sua geração ocasionalmente iam para a universidade e as que a frequentavam eram todas de famílias abastadas que podiam pagar a escola preparatória. ${ }^{12}$ Ainda segundo sua biógrafa,

\footnotetext{
${ }^{6}$ Quando se casou com Annie Healy, em 1881, Thomas Barnacle assinou o registro com um X. Cf. Maddox, Brenda, op. cit., p. 9.

${ }^{7}$ Joyce e Michael Healy (1862-1907) se tornariam grandes amigos.

${ }^{8}$ Ellmann, Richard (org.). Selected Letters of James Joyce. Nova York: The Viking Press, 1975, p. 45.

${ }^{9}$ A avó de Nora teria lhe dado uma boa educação (bons modos à mesa, bons modos no falar).

${ }^{10}$ Maddox, Brenda, op. cit., p. 12.

${ }^{11}$ Idem, p. 13.

12 Idem, ibidem.
} 
Nora ficaria muito surpresa de saber que a posteridade iria tachá-la de relaxada, inculta, alguém que não sabia sequer cozinhar. Com o passar dos anos as zombarias se acumularam: "Ela nunca dominou a língua dos países onde eles viveram"; "Essa mulher rude e inculta (ela era uma camareira quando ele a conheceu)... se recusou a ler Ulysses ou qualquer outra coisa do seu marido"; "Nora era incapaz de dar um mínimo de tranquilidade aos familiares ou de garantir o asseio ou a organização da casa"; "Ela, como Molly Bloom, deixava a casa suja". ${ }^{13}$

Numa de suas cartas a Nora, Joyce afirma, contudo, que:

Talvez seja na arte, Nora queridinha, que você e eu encontremos um conforto para o nosso amor. Eu gostaria de te ver cercada por tudo que é fino e belo e nobre em arte. Você não é, como diz, uma pobre moça sem educação. Você é a minha noiva, querida, e quero te dar todo o prazer e toda a alegria nesta vida que eu puder.

Numa outra carta, endereçada ao irmão Stanislaus, Joyce no entanto afirma, com certo desalento: "Li para Nora o capítulo XI que ela achou extraordinário mas ela não se interessa nem um pouco pela minha arte". ${ }^{14} \mathrm{E}$ numa terceira carta, de 1912, Joyce diz o seguinte:

Quando voltarmos para Trieste você lerá se eu te der livros? Então nós poderemos conversar sobre eles. Ninguém te ama como eu e adoraria ler contigo os diferentes poetas e dramaturgos e romancistas como o seu guia. Eu te darei apenas o que é mais belo e melhor em literatura.

O escritor Arthur Power certa vez declarou que era "verdade que ela não era uma intelectual de modo algum; e por que deveria?... Ela era sincera e uma mulher garbosa [...] - essa brisa de Galway no ar intelectual de sua casa em Paris". 15

Pouco se sabe sobre a vida de Nora entre o período de sua saída da escola e sua ida para Dublin. Concluídos os anos escolares, as irmãs do Presentation Convent ofereceram a Nora um trabalho como porteira nessa instituição, mas Nora não ficou ali todos os anos: também trabalhou como doméstica na casa de um médico e na oficina de encadernação O'Gorman's, razão pela qual, mais tarde, Joyce enviou uma primeira edição autografada de Ulysses para O'Gorman's. ${ }^{16}$

Numa das cartas enviadas a Stanislaus, Joyce conta uma história surpreendente sobre a vida de Nora neste período:

Quando ela tinha dezesseis anos um cura de Galway criou um laço de amizade com ela: chá no presbitério, conversinhas, familiaridade. Era um jovem bonito com cabelos pretos encaracolados. Uma noite durante o chá ele a colocou no seu colo e disse que gostava dela, que ela era uma garotinha bonita. Então ele colocou sua mão dentro do seu vestido que era relativamente curto. Ela,

\footnotetext{
${ }^{13}$ Idem, p. 376.

${ }^{14}$ Ellmann, Richard (org.), op. cit., pp. 46-47.

${ }^{15}$ Maddox, Brenda, op. cit., p. 376.

${ }^{16}$ Maddox, Brenda, op. cit., pp. 13 e 20.
} 
entretanto, eu concluo, fugiu. Mais tarde ele lhe disse que falasse em confissão que foi um homem e não um padre que "fez" isso com ela. Grande diferença. ${ }^{17}$

Mais tarde, Nora teria se envolvido com um rapaz protestante, mas a família proibiu que seus encontros com ele continuassem: seu tio "bateu nela com uma bengala grande. Ela desmaiou no chão e se agarrou nos seus joelhos. Nessa época ela tinha dezenove! Historinha bonita, né?"18

Joyce conheceu Nora em 10 de junho de 1904, quando ambos caminhavam pela Nassau Street, em Dublin. Depois de conversarem um pouco, Joyce ficou sabendo que Nora, uma bela moça de cabelos castanhoavermelhados, estava empregada no Finn's Hotel, e que, pelo sotaque, devia ser de Galway. Então marcaram um encontro na esquina da Marion Street, no dia 14 de junho. ${ }^{19}$ Nora não apareceu e, no dia 15 , Joyce lhe escreveu sua primeira carta: ${ }^{20}$ "Devo estar cego. Olhei para uma cabeça com cabelos castanhoavermelhados durante um bom tempo e decidi que não era a sua. Voltei para casa desolado". Joyce e Nora saíram juntos pela primeira vez no dia 16 de junho, data imortalizada no romance Ulysses, cujo enredo se passa nesse dia. O namoro engrenou, e os encontros amorosos se sucederam, cada vez mais ardentes.

Joyce e Nora partiram para Londres no final de 1904, pois Joyce pretendia se encontrar com Arthur Symons e discutir com editores a publicação de seu livro de poesia Música de câmara. ${ }^{21}$ Segundo Richard Ellmann, quando o casal foi a Londres, um ainda não confiava plenamente no outro. Quando chegaram à cidade, Joyce deixou Nora durante duas horas num parque enquanto foi procurar Arthur Symons. "Ela pensou que ele não voltaria. Mas voltou, e surpreenderia seus amigos, e talvez até a si mesmo, com a futura constância. Quanto a Nora, ficou firme pelo resto da vida". ${ }^{22}$

Depois disso o casal quase não se separou (Joyce oficializou sua união com Nora em 1931), a exceção foi o ano de 1909, quando Joyce fez duas viagens à Irlanda, enquanto Nora permaneceu em Trieste. ${ }^{23}$ São dessa data a maior parte das cartas que se encontram neste volume.

A impressão de seu país - "Meu amor Como estou farto, farto, farto de Dublin! É a cidade do fracasso, do rancor e da infelicidade. Eu anseio sair daqui" -, suas dúvidas em relação à vida passada de Nora - "Georgie é meu filho?", a dependência em relação a Nora - "Me salve, meu grande amor! Me salve da maldade do mundo e da maldade do meu próprio coração!" -, são temas constantes das cartas de Joyce enviadas a Nora. Chamam a atenção também as cartas obscenas, as quais teriam sido incentivadas, em parte, por sua própria companheira. Mas é a fantasia erótica do próprio Joyce que sobressai nelas:

\footnotetext{
${ }^{17}$ Ellmann, Richard (org.), op. cit., pp. 45-46.

${ }^{18}$ Ellmann, Richard (org.), op. cit., p. 46.

${ }^{19}$ Nora sempre contava a história de como conheceu Joyce, mas cada vez de um modo diferente.

${ }^{20}$ Ellmann, Richard. James Joyce. São Paulo: Globo, 1989, p. 205.

${ }^{21}$ Ellmann, Richard, op. cit., p. 235.

${ }^{22}$ Ellmann, Richard, op. cit., p. 232.

${ }^{23}$ Maddox, Brenda, op. cit., p. 89.
} 
Fiquei feliz em saber que você gosta realmente de ser fodida por trás. Sim, agora me lembro daquela noite em que te fodi demoradamente por trás. Foi a trepada mais suja de que me lembro, querida. Meu pau ficou enfiado em você por várias horas, entrando e saindo do teu rabo virado para cima. Sentia as tuas gordas nádegas suadas sob a minha barriga e via a tua face rubra e os teus olhos enlouquecidos.

Como se lê em Nora: the real life of Molly Bloom, a astuta Nora "se empenhou nessas correspondências obscenas para mantê-lo longe das prostitutas. Joyce tinha tido uma doença venérea quando ela o conheceu. Talvez ele voltasse, Nora temia, a ter relações com prostitutas de Dublin quando ele estivesse longe dela, talvez ele reavivasse a sua infecção passando-a possivelmente para ela". ${ }^{24}$

Brenda Maddox lembra ainda que "a predileção sexual de Nora não parecia ser por sexo anal, mas ela queria segurar seu homem, queria lhe arrancar dinheiro e gostava de jogos sexuais. Uma vez ele se queixou porque sua carta estava inesperadamente fria; ele lhe enviou um outro bilhete de banco". ${ }^{25}$ Joyce ficava em êxtase quando Nora lhe escrevia: "Você diz que quando eu voltar vai me chupar e que quer que eu lamba a tua xoxota, sua salafrária depravadinha".

No prefácio à edição francesa das cartas para Nora, assinada pelo estudioso e tradutor André Topia, lemos algo que merece ser destacado aqui, pois sobre isso todos os especialistas em Joyce estão de acordo: que "raramente na história da literatura um encontro amoroso teve tanta repercussão no conjunto de uma obra. A figura de Nora frequenta com efeito toda a ficção de Joyce, de Dublinenses a Finnegans Wake". ${ }^{26}$

Nora teria inspirado, por exemplo, a personagem Gretta, mulher de Gabriel Conroy, no conto "Os mortos", pois, assim como ela, teria também vindo de Galway, além do que, como conta Joyce numa carta de 3 de dezembro de 1904 a Stanislaus, "ela teve muitos casos de amor, um quando ela era muito jovem, com um garoto que morreu. Ela ficou de cama com a notícia de sua morte". 27

Segundo Gordon Browker, um namorado de Nora, Michael Feeney, teria também morrido em virtude de uma pneumonia, depois de esperar longamente por Nora, na saída do Convento da Apresentação, onde ela trabalhava, sob uma forte chuva. Quando Nora soube, dois meses depois, da morte de Feeney, sentiu-se culpada e "estava convencida que ele morreu porque a amava". 28

Nora teria inspirado também a criação de Bertha, na peça Exilados, uma personagem que, como Nora, leva seu companheiro a mergulhar numa interminável e angustiosa dúvida sobre sua fidelidade amorosa.

Anna Livia, protagonista de Finnegans Wake, seria, como Nora Barnacle, a grande "amanteretriz". É possível ver refletidas em Anna Livia várias características de Nora: seu cabelo castanho-avermelhado, seu gosto por

\footnotetext{
${ }^{24}$ Maddox, Brenda, op. cit., p. 102.

${ }^{25}$ Idem, p. 105.

${ }^{26}$ Joyce, James. Lettres à Nora. Paris: Payot \& Rivages, 2012, p. 7.

${ }^{27}$ Ellmann, Richard (org.), op. cit., p. 45.

${ }^{28}$ Browker, Gordon. James Joyce: a new biography. Nova York: Farrar, Straus and Giroux, 2011, p. 122.
} 
vestidos e, em particular, por sapatos. Anna Livia é, ao mesmo tempo, santa e meretriz, por isso cabe voltar à correspondência de Joyce, na qual ele, num momento, chama Nora de santa - "Guie-me, minha santa, meu anjo" - para, em seguida, tratá-la como uma devassa - "Minha doce putinha".

Anna Livia seria também aquilo que Nora foi enquanto Joyce escrevia sua obra máxima, já nos derradeiros anos de sua vida, Finnegans Wake: bonita e feia, cansada e solitária, consumindo sua vida na dedicação aos filhos e ao esposo.

Quanto a Molly Bloom, a grande personagem de Ulysses, nascida em Gibraltar e filha de mãe espanhola, não se parecia com Nora: seu cabelo preto seria uma referência a uma sedutora pupila de Joyce em Trieste, Amália Popper, a quem ensinou inglês; seu aspecto espanhol-irlandês viria da filha de um amigo do pai de Joyce. A potente voz de cantora viria de uma matrona de Dublin... A última palavra do seu famoso monólogo, "Sim", teria sido pronunciada por uma amiga de Nora, Lillian Wallace, num encontro com amigos: Joyce a teria ouvido dizer "Sim" várias vezes. ${ }^{29}$

Embora Joyce nunca tenha afirmado que Molly era o retrato de Nora, com certeza a linguagem do monólogo final de Ulysses foi parcialmente calcado no estilo das cartas de Nora, que, embora ainda não divulgadas na íntegra, eram compostas, conforme afirmam os biógrafos, com frases longas, desconexas e sem pontuação (as cartas de Joyce a Nora, aliás, tampouco obedecem às regras gramaticais nesse quesito). ${ }^{30}$ Além disso, tanto Molly quanto Nora recebiam e apreciavam cartas obscenas escritas por seus respectivos maridos.

Voltando à ascendência espanhola de Molly, caberia destacar que Joyce, no ensaio "A cidade das tribos", lembra que os habitantes de Galway, terra de Nora, são de origem espanhola. Embora em Galway não se tope "com o verdadeiro tipo espanhol de traços e cabelos negros como um corvo a cada quatro passos que se dê", ${ }^{31}$ é bem possível que os seus escombros (as casas espanholas já estavam desmoronando, como frisou Joyce) tenham vindo à tona em Ulysses, ao redor da figura de Molly Bloom.

Entre os muitos tributos a Nora na obra de Joyce, sobressaem as referências, muitas vezes obscuras, a aves marinhas e gansos - "glorious name of Irish goose" (Finnegans Wake) -, uma vez que o sobrenome da sua musa, Barnacle, viria de uma ave marinha, barnacle goose (bernaca), que vive no Ártico e migra para os estuários da Grã-Bretanha e da Irlanda durante o inverno. $^{32}$

A importância de Nora foi tanta na ficção de Joyce, e sua pessoa tornou-se tão inesquecível para os leitores, que Kenneth Reddin escreveu no Irish Times, quando o escritor morreu: "Lembro da bela voz de Galway da sra. Joyce, da sua hospitalidade e do constante bom humor... e do sentimento imutável de uma Dublin transplantada para o exterior". ${ }^{33}$

\footnotetext{
${ }^{29}$ Maddox, Brenda, op. cit., p. 198.

${ }^{30}$ Idem, p. 199.

31 JOYCE, James. De santos e sábios: escritos estéticos e políticos. Sérgio Medeiros e Dirce Waltrick do Amarante (orgs.). São Paulo: Iluminuras, 2012, p. 243.

${ }^{32}$ Maddox, Brenda, op. cit., pp. 09-10. Barnacle, em inglês, também significa craca, percevejo.

${ }^{33}$ Idem, p. 374.
} 
Sua própria morte, anos depois, foi anunciada na imprensa mundial. Os biógrafos citam, por exemplo, no que se refere ao universo de língua inglesa, publicações importantes como The New York Times, The Herald-Tribune, o Times of London e a revista Time, que, em 23 abril de 1951, concedeu-lhe alguns dos raros créditos públicos sobre as realizações literárias de Joyce:

Faleceu: Sra. James Joyce (Nora Barnacle), $65,{ }^{34}$ durante longo tempo confidente e companheira literária de seu famoso marido escritor; de um ataque cardíaco; em Zurique, Suíça, onde Joyce faleceu há dez anos. Uma mulher prática, ajudou-o a se estabelecer e a terminar sua obra, suspirou depois de ler Ulysses: "Acho que esse homem é um gênio, mas que mente suja ele tem!" Depois da morte do marido já célebre autor, suportou longa e decente pobreza, relutando em morar na Inglaterra e incapaz de receber mais do que uma fração de seus direitos autorais fora do país. ${ }^{35}$

Dirce Waltrick do Amarante dwa@matrix.com.br Profa. doutora, Universidade Federal de Santa Catarina

\footnotetext{
${ }^{34}$ Na realidade, Nora tinha 67 anos.

${ }^{35}$ Maddox, Brenda, op. cit., pp. 374-375.
} 